\title{
Obesidade: possibilidades de existir e práticas de cuidado'
}

\section{Obesity: possibilities of developing and care practices}

\author{
Flávia Maria Araujo ${ }^{a}$ \\ (iD) https://orcid.org/0000-0002-3813-5539 \\ E-mail: araujoflavia.mळgmail.com
}

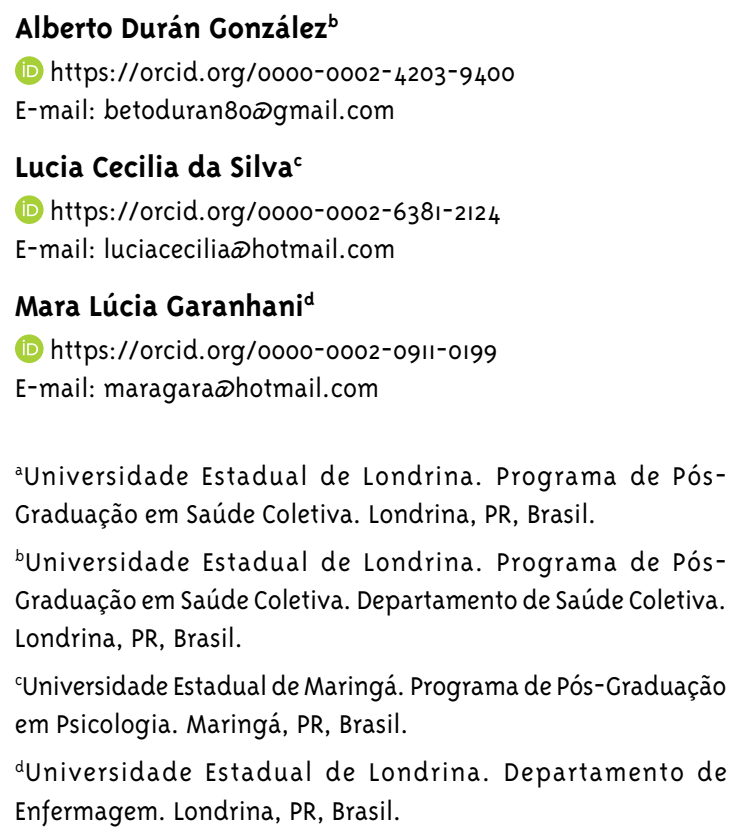

\section{Resumo}

A obesidade apresenta origem multifatorial e é bastante frequente no Brasil. Hábitos alimentares podem refletir conflitos psíquicos que influenciam diretamente as práticas de cuidado, especialmente a dieta e a atividade física. A obesidade expressa formas de ser; segundo Merleau-Ponty, por meio do corpo, o homem vivencia o mundo - o corpo carrega valores e percepções. Com o objetivo de compreender quais comportamentos são vividos como cuidado pelas pessoas obesas e quais são as implicações disso para a prática profissional em saúde, realizamos uma pesquisa qualitativa com pessoas obesas em grau I e II, sete homens e cinco mulheres. Foram realizadas entrevistas que foram gravadas, transcritas e posteriormente analisadas por meio da análise do discurso. Os resultados foram divididos em três categorias: (1) tomada de decisão em cuidar-se ou não, revelando o momento de iniciar o cuidado e os fatores que influenciam essa decisão; (2) vivência das formas de cuidado, revelando possibilidades e dificuldades encontradas na execução do cuidado; e (3) emagrecimento como opção ou obrigação, questionando motivações para cuidar-se pela saúde ou atender a padrões estéticos. Concluímos que existem várias possibilidades de cuidado e vivência da obesidade; também observamos a necessidade de abordagens que compreendam as particularidades desse fenômeno. Palavras-chave: Obesidade; Cuidado; Maurice Merleau-Ponty.

\section{Correspondência}

Flávia Maria Araujo

Universidade Estadual de Londrina, Programa de Pós-Graduação em Saúde Coletiva. Av. Robert Koch, 60, Vila Operária. Londrina, PR, Brasil. CEP 86038-350.

1 Financiamento: bolsa estudantil da Coordenação de Aperfeiçoamento de Pessoal de Nível Superior (Capes). 


\section{Introdução}

Obesity has a multifactorial origin and is quite frequent in Brazil. Eating habits may reflect psychic conflicts, which directly influence care practices, especially diet and physical activity. Obesity expresses ways of being: according to Merleau-Ponty, through the body, man experiences the world, the body carries values and perceptions. To understand which behaviors are experienced as care by obese people, and which implications it has for professional practice in health, we conducted a qualitative study with obese people in grades I and II, seven men and five women. Interviews were recorded, transcribed and later analyzed by the Discourse Analysis Method. The results were divided into 3 categories: (1) decision-making in caring for themselves or not, reveals the moment of initiating care and factors influencing such decision; (2) experience of forms of care: possibilities and difficulties, revealing possibilities and difficulties found in the provision of care; and (3) weight loss as an option or obligation, questioning of motivations to take care of oneself, due to health or to meet aesthetic standards. We conclude that several possibilities of care and experience of obesity exist. We also observe the need for approaches that understand the particularities of this phenomenon.

Keywords: Obesity; Care; Maurice Merleau-Ponty.
A obesidade é uma condição de saúde com dados expressivos no Brasil: afeta 18,9\% dos adultos brasileiros, conforme a pesquisa Vigilância de Fatores de Risco e Proteção para Doenças Crônicas por Inquérito Telefônico (Brasil, 2018), realizada pelo Ministério da Saúde em 2017. Sua etiologia é marcada pela influência de fenômenos da vida moderna, como rotinas agitadas (López; Ramírez; Sánchez, 2014) e a cultura de consumo (Pinho et al., 2012). Dada a natureza complexa da obesidade, a responsabilidade por ela deve ser pensada como fenômeno social - por isso, políticas públicas têm sido promovidas no Brasil para intervir coletivamente na promoção de um estilo de vida mais saudável (Paim et al., 2011).

Diante desse panorama, a obesidade pode ser considerada doença de difícil tratamento e controle, devido à complexidade que abarca. 0 cuidado preconizado para pessoas obesas é amplo e implica algumas mudanças no estilo de vida, rumo à promoção de saúde (Vieira; Turato, 2010). Há várias possibilidades de cuidado para a obesidade, como dietas e reeducação alimentar - entretanto, sua realização apresenta dificuldades e essas práticas são perpassadas por aspectos emocionais. Os hábitos alimentares podem refletir dificuldades psíquicas e ser veículo de expressão e alívio para obesos (Vieira; Turato, 2010).

Estudos (Del Ciampo et al., 2010; Pinto; Bosi, 2010) mostram que pessoas obesas costumam tentar diferentes métodos para reduzir o peso, por vezes sem considerar sua saúde. Entre eles, encontramos dietas da moda, exercícios físicos extenuantes, medicamentos sem prescrição e intervenções indicadas por conhecidos ou pela mídia. Entretanto, eles não atingem o resultado esperado, o que pode gerar frustração e tristeza.

Olhando para essas tentativas de cuidado, vemos mais que frustração: percebemos o desejo de cuidarse. Deve-se buscar o olhar para além do diagnóstico de obesidade, incluindo uma forma de ser, de existir, sem desconsiderar a necessidade de cuidados com a saúde desse corpo.

Refletimos sobre o corpo obeso baseados no referencial filosófico de Maurice Merleau-Ponty (1908-1961). O filósofo faz uma leitura para além dos 
aspectos biológicos, abordando usos e significados que são diferenciados para cada pessoa. Segundo Merleau-Ponty (2011), o corpo, antes de ser objeto, é nosso modo próprio de ser-no-mundo. O homem se abre ao mundo e o vivencia pelo corpo, se enraíza no mundo por meio dele, tornando-se inseparável deste. Merleau-Ponty o denomina "corpo próprio", pois é aquele que carrega os valores e as percepções do ser. O corpo próprio também é chamado de "corpo vivido", "um conjunto de significações vividas" (Merleau-Ponty, 2011, p. 212), aquele que vive e sente as experiências do ser.

A forma como o corpo próprio se porta no mundo, como ele se adapta e responde em seu contexto existencial, é o corpo habitual, aquele que possui proximidade, familiaridade; lidamos com ele todos os dias. Mas o habitual nos fala também de rupturas com a familiaridade. Assim, pode surgir o corpo atual, aquele que sofre mudanças, como ganhar ou perder peso, sofrer uma doença ou curar-se. Quando o corpo atual se faz presente, é necessário aprender a lidar com ele (Merleau-Ponty, 2011).

Articulando a problemática que cerca as tentativas de emagrecimento e o referencial teórico, despontam os cuidados que a obesidade requer, subsidiando as perguntas de pesquisa que realizamos com pessoas obesas: quais ações sobre o corpo são percebidas como cuidado nestas, e como se dá a ação desse cuidado? Quais são as implicações dessas percepções na atuação dos profissionais da área da saúde?

Portanto, este artigo aborda as experiências de cuidado com o corpo obeso tendo os seguintes objetivos: identificar ações sobre o corpo que são percebidas como cuidado em pessoas obesas e analisar as implicações dessas percepções para a atuação dos profissionais da área da saúde.

\section{Metodologia}

Pesquisa qualitativa de abordagem fenomenológica, realizada por meio de "uma trajetória circular em torno do que se deseja compreender" (Garnica, 1997, p. 111). A fenomenologia busca compreender a realidade como ela se apresenta, captando a essência de seu objeto de estudo, desvelando elementos significativos pertencentes, no caso desta pesquisa, ao fenômeno "ser obeso".
Os critérios de inclusão para os informantes foram: pessoas obesas em grau I - índice de massa corporal (IMC) de $30 \mathrm{~kg} / \mathrm{m}^{2}$ a $34,9 \mathrm{~kg} / \mathrm{m}^{2}$ - e II - 35 $\mathrm{kg} / \mathrm{m}^{2}$ a $39,9 \mathrm{~kg} / \mathrm{m}^{2}$-, de acordo com a Organização Mundial da Saúde (OMS) (Abeso, 2009), de ambos os sexos, na faixa de 44-6o anos, de diferentes classes sociais. Os participantes foram escolhidos considerando obesidade em grau I e II por ser possível identificar características que permitem aprofundar a compreensão da relação dos obesos com seu corpo, algo somado a questões do início do comportamento que leva à obesidade, o que pode contribuir para intervenções mais eficazes em saúde.

Os informantes foram localizados por meio do banco de dados da pesquisa VigiCardio: doenças cardiovasculares no estado do Paraná: mortalidade, perfil de risco, terapia medicamentosa e complicações (Souza et al., 2013), com a devida autorização do coordenador da investigação. Todos os informantes residem em uma mesma cidade de médio porte.

O primeiro contato com os informantes foi feito por telefone, ocasião em que se explanou o objetivo da pesquisa. Em seguida, foi feito o convite e agendada a entrevista, de acordo com a conveniência de cada um. O período de coleta de dados se deu entre os meses de março e setembro de 2015.

Esta pesquisa é fruto da dissertação de mestrado de Flávia Maria Araujo, orientada pela professora doutora Mara Lúcia Garanhani, intitulada Relação indivíduo-corpo na obesidade: análise sob o olhar de Merleau-Ponty. O projeto foi aprovado pelo Comitê de Ética em Pesquisa Envolvendo Seres Humanos da Universidade Estadual de Londrina. Não há conflitos de interesse. Todos os participantes foram voluntários e assinaram o Termo de Consentimento Livre e Esclarecido.

Participaram da pesquisa 12 informantes, cinco mulheres e sete homens, que foram entrevistados em seus domicílios. Em um ambiente de privacidade, iniciou-se o procedimento com algumas perguntas para caracterização, como estado civil e condições de saúde. Em seguida, focou-se nas questões centrais: "Você costuma cuidar de seu corpo?" e "Como realiza esse cuidado?".

As entrevistas foram gravadas, transcritas na íntegra e submetidas à análise de discurso, por meio da técnica de estrutura do fenômeno situado 
(Garnica, 1997; Martins; Bicudo, 2005), que propõe dois momentos para exame: a análise ideográfica ou individual das narrativas e a análise nomotética ou geral. Dentro dessa modalidade, são considerados os determinantes filosóficos e sociais do sentido do discurso.

O processo de análise envolveu o movimento de um "círculo hermenêutico", um ir e vir das partes para o todo e do todo para as partes, tentando compreender o fenômeno em suas diferentes nuances. 0 referencial teórico utilizado foi a abordagem fenomenológica de Maurice Merleau-Ponty.

\section{Resultados e discussão}

Apresentaremos os resultados em três categorias: a primeira mostrando o momento de despertar para a necessidade do cuidado com o corpo, a segunda retratando as formas de cuidado e as dificuldades que trazem e a última refletindo acerca da legitimidade dos motivos que levam ao desejo de perder peso.

\section{Categoria I: a tomada de decisão em cuidar-se ou não}

Quando a obesidade se faz presente, uma reação inicial comum das pessoas é ignorá-la, tratar seu corpo como um corpo não refletido. Nesse momento, a obesidade não existe na percepção do obeso; ocorre negação da condição do corpo e, portanto, há um corpo que não demanda cuidados, como nesta fala. Não tem problema, e o peso... aaa está normal [...]. Não é muito que incomoda [...]. Eu vivo bem (H3).

A fala representa o momento de não viver a obesidade. Embora esteja com o IMC nessa faixa, o participante $\mathrm{H}_{3}$ se mostra numa fase em que não a tem no corpo vivido.

Observamos que a pessoa obesa inicia o processo olhando para seu corpo de forma não refletida, não percebendo a obesidade como algo a ser cuidado. Esta não fazia parte de seu corpo próprio, e não vivia como obeso - portanto, também não estava em seu corpo vivido. Quando essa forma de ver é superada, inicia-se o cuidado com o corpo por meio de várias alternativas, desde o cuidado realizado pela experiência do indivíduo até o orientado por profissionais de saúde, incorporando, devagar, a obesidade no corpo vivido.

Esse início do processo em negação pode ser entendido como uma forma de começar a lidar com a obesidade (Costa et al., 2012). Isso não significa que a pessoa desconhece o que acontece com ela, mas apenas que precisa de um tempo para conseguir lidar com isso (Costa et al., 2012) - lembrando que o desenrolar do processo pode acontecer em círculos, entre a negação e o cuidado.

Em um segundo momento, a obesidade passa a fazer parte desse corpo; nesse momento, a consciência desperta para a necessidade de cuidados. Essa transição é de grande importância para a tomada de decisão em cuidar-se; somente depois que ela acontece os cuidados começam a ser executados. Embora a transição seja importante, o processo pode não ocorrer em linha reta: pode haver um "ir e vir" entre as posições de cuidar e não cuidar.

Foi possível observar que esse processo de tomada de decisão sofreu influência de alguns aspectos, que atuaram criando oportunidades para isso. A ocorrência de doenças associadas, como diabetes e hipertensão, foram oportunidades para perceber o corpo como obeso e merecedor de cuidado.

A preocupação com a saúde aparece como fator facilitador para o início do processo de despertar para o corpo. Após alguns exames alterados, surge a realidade de que a saúde está sendo prejudicada. Então, a consciência volta-se ao corpo.

A gente caiu em si e começou tomar esses cuidados [...]. É mais em função do cuidado com a saúde com o corpo [...]. Não é fácil a gente deixar aquilo que gosta, mas a gente sabe que énecessário, pesa mais a preocupação com a saúde, com o corpo [...], vai superando o desejo e a vontade de comer as coisas proibidas [risos]. (H1)

o médico falou, explicou todos os problemas, então você cria uma consciência [...]. Éclaro quevocêsabe que

2 H identifica os homens, M identifica as mulheres. 
sevocêengordar, se vocêfor sedentária, vai acontecer alguma coisa [...], mas você só fica atenta quando acontece [...]. A gente acha que nunca vai chegar lá. (M1)

Conforme as falas dos colaboradores e os achados de Vieira e Turato (2010), o aparecimento de outras doenças associadas à obesidade contribui para o início do processo de cuidar-se. Nossos colaboradores apresentaram menor rejeição às doenças associadas do que à obesidade - talvez por isso seja mais fácil cuidar daquelas do que desta. Além disso, essas doenças também desencadeiam preocupações mais imediatas, pois a ameaça à saúde se torna mais real. Doenças associadas funcionaram como gatilhos para perceber o corpo como obeso e incluir esse aspecto no corpo próprio. Desse modo, o corpo passa a ser vivido como obeso quando executam os cuidados com ele, despontando experiências de corpo vivido, como dificuldades e êxito.

Dessa maneira, foi revelada também a procura dos participantes por cuidados apenas quando se sentiam doentes, quando não conseguiam mais seguir com seu dia a dia. A obesidade, algumas vezes, não foi motivo de cuidado: ela por si só não conseguiu fazer com que os indivíduos olhassem para seu corpo. Alguns passaram a se preocupar consigo mesmos apenas quando surgiram outras doenças associadas, então o cuidado passou a ser em torno delas, e não da primeira. Estou sentindo uns problemas há uma semana, um mês [...]. Eu penso assim, você está bem, continua trabalhando; não melhorou, precisar do médico, vocêvai $\left(\mathrm{H}_{3}\right)$.

\section{Categoria 2: vivenciando as formas de cuidado: possibilidades e dificuldades}

As possibilidades de cuidado reveladas expressam a perspectiva de cuidado para os indivíduos informantes desta pesquisa. Consideramos "cuidado" toda ação que teve o intuito de proporcionar atenção e melhorias na condição de seus próprios corpos.

As diferentes formas de cuidado reveladas vieram acompanhadas de dificuldades em executá-las. Embora, muitas vezes, os participantes não tenham conseguido obter os resultados que desejavam, não deixaram de realizar ações por eles compreendidas como cuidadosas. Por vezes, continuaram sem modificações no peso, testemunharam períodos de oscilações, tiveram alguns dias com ânimo e outros não. Abordaremos, então, também as dificuldades.

Eu cuido, eu não tomo remédio [...], só tomo quando dá uma dor de cabeça, o máximo que eu tomo é analgésico, nada mais. $\left(\mathrm{H}_{3}\right)$

Eu não quero ser dependente de remédio [...]. Se vocêpôr na sua cabeça, você vai ser dependente para o resto da tua vida! Então eu não quero isso para mim [...]. Se Deus quiser, eu não vou ser dependente de remédio. $\left(\mathrm{M}_{3}\right)$

Para esses informantes, não utilizarmedicamentos é uma forma de cuidado consigo mesmo. Os medicamentos são entendidos como intrusos, nocivos e causadores de dependência, além de sinalizarem um estado mais avançado da obesidade. As pessoas guardam e respondem ao que aprenderam com a família e a experiência de vida, não seguindo prescrições de profissionais de saúde. MerleauPonty (2011) prevê esse fenômeno, explicando que a experiência vivida pode atuar de maneira mais forte que a ciência.

As dietas foram apontadas como formas de cuidado ou de simplesmente evitar alimentos que prejudicam. Os participantes também fazem exercícios, o que mostra que a dificuldade em perder peso não passou pela falta de informação.

Há um ano e pouco eu vim equilibrando isso, de comer bem menos [...]. Hoje eu tenho consciência do tantinho de comida que eu devo comer [...], com arroz feijão. Eu queria ser zero à noite. $\left(\mathrm{H}_{4}\right)$

Eu faço ginástica [...], faço alongamento [...]. Falam que atividade física é bom, então eu estou fazendo [...]. Procuro fazer bastante salada e procuro não fazer fritura. (M2)

A gente sabendo do quadro de hipertensão que eu tenho particular, eu evito muita coisa, fritura, salgado fora de casa. $\left(\mathrm{H}_{7}\right)$

Esse processo de perceber o corpo obeso, de trazer novo significado ao corpo próprio e ao vivido, é perpassado por sentimentos, e os hábitos alimentares 
refletem aspectos emocionais (Pinto; Bosi, 2010). Mudar hábitos significa mudar sentimentos, o que é um processo difícil e lento.

Nem sempre o cuidado está relacionado a estética. $\mathrm{H}_{7}$, por exemplo, relatou fazer dieta e caminhadas, mas não manifestou desejo de perder peso, embora também não esteja ganhando: seu peso está estável há alguns anos. Ele não tem objetivos estéticos com o cuidado, apenas de saúde. Apesar de estar obeso, ele consegue executar todas as suas tarefas sem dificuldades; faz o cuidado e sente-se saudável, por isso não se preocupa em perder peso.

Observamos que os participantes da pesquisa executam cuidados, mas há dias em que as dificuldades superam a motivação de realizá-los, então não há constância. Entretanto, ainda assim há cuidado: não podemos desconsiderar o esforço empenhado.

Vou fazer ginástica com muita preguiça! Torcendo para que alguém fale que não vai ter aula hoje, mas estou tentando [...]. Tenho muita preguiça de andar, principalmente se for sozinha! [...] A gente sabe que é bom, mas não faço! Não tenho força de vontade, não consigo não! (M2)

Temos também aqueles que conseguiram perder peso, e não ganhar novamente, por meio da mudança na alimentação e da prática de exercícios. Depois do processo feito, sentem-se bem - mas observamos que a perda de peso é difícil, pois somente dois dentre os informantes a conseguiram realizar.

Você começa [a] fazer a comparação do que era e do que é, a gente olha no espelho e percebe que não tem mais aquela coisa [mostrando a barriga]. $\varepsilon$ consegui, vim para 93 quilos [...]. No início de 2014, eu estava com 101 quilos. Aícheguei a 93 agora, pesei na última avaliação, um ano, mais ou menos. (H1)

Antes eu estava com 100 e alguma coisinha, já consegui eliminar [...] uns cinco quilos, seis [...] com muito custo; com caminhada foi abaixando o peso [...]. Agora estou bem! Melhorando né, tem que melhorar mais, tentando volta[r] uns $90 .\left(\mathrm{H}_{5}\right)$

Dentre as pessoas que se cuidam utilizando os serviços de saúde, houve variadas perspectivas.
Observamos aqueles que frequentavam com tranquilidade, mostrando percepção positiva do serviço, bem como aqueles que frequentavam e percebiam o serviço como uma dificuldade para o cuidado.

Uma das informantes apresentou-se bastante refratária a qualquer tipo de tratamento prescrito por profissionais de saúde. Ela faz seu próprio cuidado, guiada por suas experiências; passa grandes períodos de tempo sem se alimentar para perder peso e não toma os medicamentos prescritos, apesar de ter passado por alguns princípios de infarto por conta de hipertensão. Observamos que o gerador de sofrimento para ela não é o formato do corpo, e sim o luto por dois filhos, que faleceram há alguns anos. Ela demonstra diminuição de vontade de viver e desafia os limites de seu corpo. Entretanto, na percepção dela, não utilizar medicamentos é algo positivo.

Quem sabe é o corpo da gente! Entendeu? O remédio para pressão, eu tomo só quando eu vejo que eu estou mesmo ruim [...]. Quando precisa de remédio, é assim [...], parece que a boca está enrolando [...], eu sinto aquela quentura no corpo, inteirinho! [...] Os dois olhos começam a formigar, parece que eu não enxergo nada! Aí eu sei que a pressão está ficando alta! (M3)

As ações de cuidado sofrem também influência de sentimentos, tanto de forma a estimular as ações quanto dificultar. Conseguir realizar as tarefas de casa, executar incumbências que exigem esforço físico e trabalhar, mesmo sendo obeso, foram sentidas como experiências de superação. Essas experiências trazem sentimentos de bem-estar, e podem melhorar a autoestima - mas, por outro lado, podem também trazer a sensação de que os obesos não necessitam de se cuidar.

Subo em escada para fazer as copas das árvores normalmente, tenho muita disposição para isso, tranquilo [...]. Exige do físico. (H4)

Por enquanto, está tudo bem ainda; faço todo o serviço, cuido de tanta coisa e está indo bem. (M4)

Crenças também podem se apresentar como fatores facilitadores ou dificuldades; são algo particular, que pode caminhar em qualquer direção. 
Eu cuido desse corpo que Deus me deu para que eu zelasse [...]. Se morrer é porque Deus quis, se ficou doente é porque Deus quis. Essa situação você tem que trabalhar. Deus realmente está acima de tudo, mas nos deu condições para cuidar desse corpo [...]. Existia uma certa resistência com relação a medicamentos, achando que era falta de fé tomar medicamentos, e hoje a gente procura passar que o medicamento também é uma provisão de Deus! Que faz nascer uma planta e permite que pessoas transforme [m] aquilo em um medicamento. (H1)

A fé religiosa pode ser benéfica para a saúde no que tange à qualidade de vida e ao encontro de propósito; pode provocar emoções positivas e promover estilos de vida saudáveis. Entretanto, pode também prejudicar ou agravar sintomas, na medida em que impede algumas formas de tratamento, provoca culpa e vergonha ou serve de justificativa para a ausência de cuidados (Panzini; Bandeira, 2007).

As orientações recebidas de profissionais da saúde, amigos e familiares também apareceram de forma expressiva. Quase todos os informantes receberam algum tipo de orientação, e todos sabiam mencionar o que fazer para perder peso. Mesmo assim, apresentaram muitas dificuldades nesse processo. Consideramos que há questões de outra natureza perpassando essa ação, como sentimentos, crenças, luto etc.

Alimentação mais controlada, menos sal, atividade física, não ficar só parado, fazer uma caminhada [...]. Cientificamente é comprovado. Os médicos pedem para perder peso. $\left(\mathrm{H}_{7}\right)$

Há 23 anos atrás, a gente nem tinha uma orientação certa; ia no médico, falava, mas achava que aquilo não ia resolver o problema e acabava não fazendo [...]. Eu ficava: "será que vai resolver?". (H6)

Os fatores sentidos como dificuldades para realizar o cuidado com o corpo foram diferenciados. O cuidado executado por meio de serviços de saúde foi um fator de influência dupla, ora agindo como facilitador, ora como dificuldade. Alguns informantes precisaram se empenhar para utilizar os serviços de saúde: foi um hábito adquirido pela necessidade. 0 fator de tempo de espera para ser atendido foi algo que trouxe relutância em frequentar o serviço, assim como a falta de confiança nele.

O postinho aqui [...] é uma pessoa que recebe bem a gente; a única coisa que eu odeio [em] ir no postinho é que fica esperando muito [...]. Você chega lá, vai fazer os exames, eles marcam daqui uns quatro, seis meses mais ou menos; consulta émesma coisa. (M3)

Muitas vezes, os informantes vivenciaram também um tratamento preconceituoso e punitivo. Enquanto seres que buscam alcançar uma nova condição para seu corpo, em diversas ocasiões sentem-se lesados quando são tratados de forma rude. Algumas vezes, ocorre intervenção proposta em tom de ordem, como se fosse algo que precisam obedecer apenas, sem escolha. A pessoa vem ali te atender assim, como se tivesse prestando um favor para você( $\left.\mathrm{H}_{4}\right)$; Semprefala: "tem que perder peso, tem que malhar!". É sempre a mesma palavra [risos] (M4).

Outro fator de influência dupla foram os sentimentos vivenciados. Por vezes, eles atuavam como fatores que dificultam o cuidado, como é o caso da ansiedade, apontada como responsável pelo aumento da vontade de alimentar-se.

Não sei se énervoso, ansiedade. Porque parece que com a ansiedade você come mais [...], eu acho que come. $\left(\mathrm{M}_{5}\right)$

Eu acho que o meu peso é por causa da ansiedade [...] no final da tarde às vezes eu exagero, cada vez que eu penso numa coisa, até na própria gordura, puta eu estou gorda, eu vou lá e pego um negócio na geladeira [...] fico pensando em algum problema aí eu vou lá, pego uma bolachinha, pego uma fruta! (M1)

Aspectos emocionais revelaram ter influência na alimentação de forma compulsiva. Em várias ocasiões, não conseguem controlar essa situação, mas há o reconhecimento de que isso existe. Percebem que os conflitos emocionais repercutem em seu corpo, pois têm forte impacto sobre o comportamento alimentar.

A gente sabe o que comer, como comer, mas tem uma coisa que parece que puxa para o lado errado! [...] 
A ansiedade, o nervoso, sei lá o quê, como chama isso... e aí eu tenho vontade de comer. (M2)

O tratamento que vocês vão ter que se fixar mais é no estresse das pessoas, no cansaço [...]. Minha cabeça roda em torno de tudo, é difícil [...]; com tudo que eu tenho na cabeça, eu não sei se o peso está no corpo ou está na mente! [...] É psicológico, muita coisa. $\left(\mathrm{H}_{3}\right)$

Nesse aspecto, algo percebido como contribuinte para o aumento da ingesta de alimentos foi a ansiedade, pois estes têm a capacidade de aplacar esse sentimento, fazendo com que a pessoa coma sem perceber, para sentir-se bem (Costa et al., 2012). Além disso, ocorre também que algumas pessoas não se dão conta da quantidade de alimento que consomem e, por isso, não conseguem fazer a conexão da obesidade com a alimentação (Pinto; Bosi, 2010). Isso pode dificultar o cuidado, pois ele fica sem razão de ser (Vieira; Turato, 2010).

Falta de tempo, cansaço após o dia de trabalho, estresse e falta de companhia para se exercitar foram outros fatores de dificuldade citados.

Não tem como eu saí [para] caminhar [...]. Eu penso que precisa fazer [...]. No final ficou por isso mesmo [...]. Às vezes, chego em casa 11 horas da noite, então eu só tenho tempo para tomar um banho e dormir. $\left(\mathrm{H}_{3}\right)$

Alguns valores e hábitos pessoais e familiares foram percebidos como barreira para cuidar-se, seja num cuidado autônomo ou acompanhado nos serviços de saúde. Comer muito era sinal de saúde até anos atrás.

Meu avô morreu com não sei tantos anos fumando até morrer [...]. Sabe que isso era saúde, poder comer de tudo [...]. Quando viam uma criança gordinha, diziam "a que lindo!". (H1)

Fuicriado assim; meu paifalava: "sevocênão precisa, você não vai, porque tem outro que está precisando" [...]. Não é só eu que penso assim. Se você pegar um pessoal da minha idade, homem, mulher não [...], você vai ver que é quase tudo a mesma resposta [...], cabeça de homem diferente de mulher. $\left(\mathrm{H}_{3}\right)$
É tudo gordo! Meu marido também. Está com 103, 104 quilos [...]. Ela [filha] gosta de comer bastante, não sei se é uma coisa hereditária, porque ela [filha] tambémé bem gordinha [...]. Nosso problemaéesse, a gente é de comer bastante; eu faço comida saudável, mas a gente não é de pegar aquele pouquinho. É todo mundo assim, gosta de comer. (M2)

Alguns fatores constituem-se em entraves para que as pessoas consigam ter uma alimentação balanceada. A vida social é um desses fatores, pois eventos com amigos e familiares envolvem sempre comida. Eu gosto de mexer na cozinha, assar uma carne; sempre gostei de preparar alimento, convidar pessoas [...]. Normalmente, quem é obeso tem uma vida social bem ativa [...]. Eu não via problema nisso num primeiro momento $(\mathrm{H1})$.

Merleau-Ponty, com seus conceitos de corpo próprio, corpo vivido, corpo atual e corpo habitual, nos leva a compreender que o corpo é algo construído pela própria pessoa em seu esquema corporal, por meio das sensações e percepções. O corpo biológico é dado pela ordem natural, mas o corpo com o qual as pessoas vivem e relacionam-se é distinto - aliás, é outro corpo construído individualmente, mas inserido em uma cultura e perpassado pelos seus valores. Desse modo, ele corrobora as falas de nossos informantes, em que os valores familiares e as experiências de vida podem ter mais influência no modo de cuidar do corpo do que recomendações de profissionais e informações sobre saúde.

\section{Categoria 3: emagrecer: uma opção ou obrigação?}

Nesta categoria, refletimos sobre o processo de perder peso. Seria ele uma opção consciente e bem informada, com o objetivo de melhorar a saúde e a autoestima, ou apenas uma obrigação de cumprir padrões pré-estabelecidos socialmente, de atender ao ideal de corpo magro?

Alguns informantes optam por não fazer o cuidado, por não querer, consciente ou inconscientemente, perder peso. Assim, apontamos para o fato de não cuidar ser uma possibilidade que deve ser respeitada.

Houve recusa em seguir o cuidado prescrito pelos profissionais, mesmo na presença de problemas considerados difíceis de lidar. A entrevistada M3 
exemplifica a situação de ficar entre o cuidar e o não cuidar. Nessas situações, apenas quando se sente diante de um problema mais sério é que busca o cuidado - assim, este não é contínuo, apenas emergencial. Quando eu vejo que eu estou passando mal, daíeu vou lá e procuro o posto... Tomo o remédio para pressão; não é todo dia não, é de vez em quando (M3).

Entretanto, observamos que a escolha do não cuidado existe também, e que essa opção pode ser feita. Algumas pessoas consideram um não fazer como cuidado, por exemplo, ao não utilizar medicamentos. Outras optam por não realizar qualquer cuidado, pois o corpo e sua saúde não são prioridades de vida.

A compreensão do ser obeso, apoiada nos conceitos de Merleau-Ponty, traz a ideia de que não se deve fazer pré-julgamentos, sendo necessário olhar para esse fenômeno como ele se mostra, em todas as suas nuances reveladas, devido a sua variabilidade e complexidade.

Observamos aqueles que não gostam de frequentar serviços de saúde por outros motivos, seja porque, apesar do peso aumentado, sentem-se bem, conseguem trabalhar e realizar as atividades domésticas, seja porque sentem que não precisam.

Então não vou ficar sentado sem ter nada! Não vou ficar tomando espaço de outro que está precisando [...]. Eu levo a vida assim, é o destino que cuida de mim [risos]. [...] Eu não tenho problema de médico nada, me sinto bem, então eu não procuro [...], não precisa preocupar. $\left(\mathrm{H}_{3}\right)$

$\mathrm{O}$ entrevistado $\mathrm{H}_{3}$ tem dores na coluna frequentemente e colesterol alto; apesar disso, sua percepção é de que está bem e não precisa de cuidados. Aparenta mais resistência em suportar dores. Essa tendência revelou-se predominantemente masculina. Observando as falas de $\mathrm{H}_{3}$ e $\mathrm{M}_{3}$, percebemos que se sentem bem, conseguem executar suas tarefas mesmo com a obesidade e não sentem necessidade de cuidar das doenças associadas.

Há também outra situação, em que o corpo e a saúde não são prioridades para o indivíduo nesse momento: ele tem outras metas e preocupações, o corpo vai ficando em segundo plano e aparece certa evitação de conscientizar-se daquilo que é necessário fazer para combater a obesidade.
Está exagerado, mas não tem como ficar cuidando disso; agora é uma época que não posso descuidar de outras coisas, o corpo vai continuar assim [...]. Não tem como pega[r] uma hora para ir na academia [...]. A minha prioridade nem é tanto minha saúde, eu acho. [...]. Eu não posso parar para pensar! Se eu parar para pensar, eu sou obrigado a levantare sair [para] caminhar todo dia, ir no médico. Então, se eu parar pra pensar, eu tenho que abandonar o resto, não tem como... $\left(\mathrm{H}_{3}\right)$

Diferentemente, outros participantes mostraramse mais ponderados, como o caso de $\mathrm{H}_{7}$, que relata realizar cuidados com sua saúde, mas não com a cobrança de ter um corpo diferente, apenas para estar saudável. Também não se sente doente, e a obesidade não é algo que o incomoda.

Tem que estar bem da cabeça, porque tem gente que o biotipo dele é esse. Não é uma desculpa, eu não fico arrumando desculpa para mim, mas também eu não posso exagerar, passar fome para querer emagrecer [...]. Não vou ficar fissurado, pôr aquilo na cabeça, "tenho que emagrecer, tenho que emagrecer!" [...]. Eu vou me preocuparassim se eu começarganharmuito peso. $\left(\mathrm{H}_{7}\right)$

Assim como demonstrado amplamente na literatura (Figueiredo, 2005; Gomes; Nascimento; Araújo, 2007; Pinheiro et al., 2002), as mulheres entrevistadas apresentaram menor resistência para o uso de serviços de saúde do que homens. Homens parecem ter relutância em indicar que necessitam de cuidados. Isso nos faz pensar numa oposição maior dos homens em cuidar de si mesmos, admitir que precisam de cuidados, embora as duas pessoas dentre os informantes que conseguiram resultado perdendo peso e não ganhando novamente foram, justamente, dois homens. Apesar de terem se apresentado mais resistentes em cuidar-se, aqueles homens que se propuseram a executar cuidados foram mais bem sucedidos do que mulheres. A respeito desse achado, podemos refletir que, talvez pela ausência de exigências estéticas, isso pode ter causado menos ansiedade - portanto, menos dificuldade para controlar a alimentação. Não, não tenho hábito de frequentar médico, posto de saúde (H5); No posto de saúde [...], para mim ébom! [...] Vou! 
Sempre que precisa, tem que trocar receita, tem que pegar remédio [...]. Tem que estar sempre indo (M2).

O corpo com o qual as pessoas obesas vivem não é somente o biológico, segundo Merleau-Ponty (2011). Pensamos no papel das equipes de saúde em intervenções nesses corpos. A equipe de saúde tem a missão de prescrever incessantemente tratamentos e dietas? Ou acolher essa pessoa e respeitar sua forma de viver e suas escolhas? Qual é a demanda que a equipe deve atender: a demanda por cuidado e respeito das pessoas pela melhoria em sua saúde ou a demanda midiática e mercadológica do corpo perfeito a qualquer custo?

Apontamos a intervenção e o cuidado ao corpo obeso como espaços para atender também os corpos próprios, vividos, atuais e habituais. Pessoas obesas necessitam de cuidado integral em saúde, pois precisam de apoio na lida com o sofrimento que vivenciam enquanto obesos (Macedo et al., 2015). Há de se buscar desviar da tendência em ter como foco somente o corpo biológico e magro, buscar intervenções que abram espaço para a diversidade e idiossincrasia humana (Mendes et al., 2014).

Para Merleau-Ponty (2011, p. 227), “doença e saúde não são modalidades da consciência ou da vontade, elas supõem um passo existencial". O filósofo aponta que os fenômenos da saúde e da doença são nuances da forma de ser de um corpo, portanto, ambas fazem parte da vida.

O foco na doença e a busca incessante por corrigila a qualquer custo, mediante o padrão do homem adulto e sadio, é criticado por Merleau-Ponty (2011). Ele propõe olhar para o doente e reconhecê-lo como um sujeito, um corpo vivo situado no mundo de suas experiências vividas, que devem ser levadas em consideração - além de reconhecer que cada ação possui sentido e intencionalidade que não pode ser vista com desprezo (Mendes et al., 2014).

O desejo de emagrecer existe, mas pode não buscar padrões estéticos pré-concebidos. Pinto e Bossi (2010) mostram que o conceito de "cura" da obesidade pode ser simplesmente perder peso para que seu corpo consiga realizar as atividades diárias e acabar com a necessidade do uso de medicamentos.

Cuidar de pessoas obesas tem sido algo difícil e com pouco sucesso na modificação da forma corporal. Para avançar nessa direção, profissionais de saúde precisam aprofundar sua compreensão dos corpos vividos e próprios, de modo a que possam incluílos em sua prática profissional. Assim, quando o profissional percebe a presença dos diferentes significados e dimensões vivenciais do corpo, ele tem a possibilidade de lhes abrir espaços em sua atuação. Quando a importância dessas vivências é legitimada, as pessoas podem trazê-las para os serviços de saúde; dessa forma, podem ser acolhidas, escutadas e tratadas. Necessitamos criar um espaço que valorize aquilo que a pessoa obesa consegue fazer por si mesma, ainda que o objetivo final não tenha sido alcançado; precisamos valorizar as pequenas vitórias durante o processo para que o ânimo não seja perdido.

Essa forma de atuação profissional a que nos referimos, que acolhe nos serviços de saúde as vivências da pessoa obesa em relação a seu corpo, é uma atuação que não se pauta exclusivamente nos protocolos e no aparato tecnológico. É uma postura profissional diante da pessoa obesa, e não a obesidade somente.

Seria um trabalho que procura pela sensibilidade e empatia, que requer valorizar os diferentes corpos e reconhecer como influenciam o cuidado consigo mesmo, além de dar importância para as percepções individuais, pois é por meio delas que se conhece o mundo. As percepções são a via do conhecimento, e é preciso legitimar essa via.

Não desconsideramos a importância do cuidado por meio de mudança de hábitos, alimentação e exercícios; apenas ressaltamos que, dada a diversidade dos fatores que influenciam o cuidado com o corpo obeso, essa é uma condição que precisa de abordagem integral, que requer intervenções de diferentes naturezas. Para isso, uma equipe com profissionais de diferentes formações é essencial para constituir a rede necessária a essa intervenção.

Compreender esses fatores e as formas particulares de cuidado pode criar uma aproximação de profissionais e pessoas obesas e contribuir para que estas olhem para seus corpos, que voltem a consciência para ele, saindo de um corpo não refletido rumo a um corpo de cuidados. Com isso, pode-se inserir o discurso científico, apontando possibilidades de caminhos a trilhar para chegar ao corpo desejado, de maneira mais próxima da 
vivência. Como nos trouxe Merleau-Ponty (2011), a experiência vivida é predominante; o conhecimento que ela permite vem antes daquele que é trazido pela ciência. Assim, trazendo a experiência das pessoas obesas para a atuação profissional, abrindo espaço para ela, é provável que consigamos melhores resultados com essa população e uma intervenção integral, de melhor qualidade.

\section{Considerações finais}

Ao final deste estudo, é possível observar que o processo de reconhecer-se como obeso é importante para a execução de cuidados com o corpo. Ele não ocorre de modo homogêneo, e sim com idas e vindas. As doenças que ocorrem em associação com a obesidade mostraram-se de fundamental importância para o cuidado, pois, a partir delas, muitas vezes, o olhar das pessoas volta-se ao corpo e à busca de cuidados.

Encontramos resultados bastante distintos em relação ao que é considerado cuidado para as pessoas obesas, o que reforça o quanto o ser humano é complexo e necessita ser melhor compreendido em suas vivências. 0 cuidado pode variar entre não utilizar medicamentos, utilizar serviços de saúde, controlar a alimentação e praticar exercícios. A ansiedade aparece como grande obstáculo para o controle da ingesta de alimentos; portanto, é um fator a ser considerado no processo.

Observamos também que muitos dos informantes reconheceram a importância de cuidar de si mesmos e tentam sempre melhorar. Apesar das dificuldades, continuavam buscando cuidar-se: estavam sempre em movimento de cuidado, oscilando entre dias em que praticam exercícios e controlam a alimentação e outros em que não conseguem realizar essas práticas. Ao longo desse processo, foram obtendo alguns sucessos, seja quando conseguiram perder alguns quilos, seja no fato de se sentirem bem e, mesmo com a obesidade, conseguirem continuar executando seu trabalho, suas tarefas domésticas, sua rotina.

Encontramos ainda pessoas que optam por não fazer o cuidado com o corpo, pois têm outras prioridades em sua vida, mesmo após o surgimento de doenças associadas. Essas escolhas, nos diz
Merleau-Ponty (2011), são formas de vida, e devem ser respeitadas, pois cada um tem sua vivência particular com seu próprio corpo. Desse modo, a atenção que deve ser prestada a pessoas obesas no que tange a serviços de saúde, precisa ser integral e considerar as vivências e idiossincrasias de cada um.

\section{Referências}

\section{ABESO - ASSOCIAÇÃO BRASILEIRA PARA ESTUDO DA OBESIDADE E DA SÍNDROME METABÓLICA. \\ Diretrizes brasileiras para obesidade: 2009/2010.}

Itapevi: AC Farmacêutica, 2009. Disponível em: <https://bit.ly/1sizaPK>. Acesso em: 22 mar. 2015.

BRASIL. Ministério da Saúde. Vigitel Brasil 2017: vigilância de fatores de risco e proteção para doenças crônicas por inquérito telefônico: estimativas sobre frequência e distribuição sociodemográfica de fatores de risco e proteção para doenças crônicas nas capitais dos 26 estados brasileiros e no Distrito Federal em 2017. Brasília, DF, 2018. Disponível em: <https://bit. ly/2QmT $7 \mathrm{Ix}>$. Acesso em: 10 fev. 2019.

COSTA, R. C. et al. Repercussões sociais no hábito alimentar dos obesos. Estudos de Psicologia, Campinas, v. 29, n. 4, p. 509-518, 2012.

DEL CIAMPO, L. A. et al. Percepção corporal e atividade física em uma coorte de adultos jovens brasileiros. Revista Brasileira de Crescimento e Desenvolvimento Humano, São Paulo, v. 20, n. 3 , p. 671-679, 2010.

FIGUEIREDO, W. Assistência à saúde dos homens: um desafio para os serviços de atenção primária.

Ciência \& Saúde Coletiva, Rio de Janeiro, v. 1, n. 10, p. 105-109, 2005.

GARNICA, A. V. M. Algumas notas sobre pesquisa qualitativa e fenomenologia. Interface: Comunicação, Saúde, Educação, Botucatu, v. 1, n. 1, p. 109-122, 1997.

GOMES, R.; NASCIMENTO, E. F.; ARAÚJO, F. C. Por que os homens buscam menos os serviços de saúde do que as mulheres? As explicações de homens com baixa escolaridade e homens com ensino superior. Cadernos de Saúde Pública, Rio de Janeiro, v. 3 , n. 23, p. 565-574, 2007. 
LÓPEZ, J. N.; RAMÍREZ, J. P.; SÁNCHEZ, P. M. La

otra cara de la obesidad: reflexiones para una aproximación sociocultural. Ciência \& Saúde Coletiva, Rio de Janeiro, v. 19, n. 6, p. 1721-1729, 2014.

MACEDO, T. T. S. et al. Percepção de pessoas obesas sobre seu corpo. Escola Anna Nery Revista de Enfermagem, Rio de Janeiro, v. 19, n. 3, p. 505-510, 2015 .

MARTINS, J.; BICUDO, M. A. V. A pesquisa qualitativa em psicologia: fundamentos e recursos básicos. São Paulo: Moraes, 2005.

MENDES, M. I. B. et al. Reflexões sobre corpo, saúde e doença em Merleau-Ponty: implicações para práticas inclusivas. Movimento: Revista de Educação Física da UFRGS, Porto Alegre, v. 20, n. 4, p. 1587-1609, 2014.

MERLEAU-PONTY, M. Fenomenologia da percepção. São Paulo: Martins Fontes, 2011.

PAIM, J. et al The Brazilian health system: history, advances, and challenges. The Lancet, London, v. 377, n. 9779, p. 1778-1797, 2011.

PANZINI, R. G.; BANDEIRA, D. R. Coping (enfrentamento) religioso/espiritual. Revista de Psiquiatria Clínica, São Paulo, v. 34, n. 1, p. 126-135, 2007.
PINHEIRO, R. S. et al. Gênero, morbidade, acesso e utilização de serviços de saúde no Brasil.

Ciência \& Saúde Coletiva, Rio de Janeiro, v. 4, n. 7, p. 687-707, 2002.

PINHO, C. P. et al. Consumo de alimentos protetores e preditores do risco cardiovascular em adultos do estado de Pernambuco.

Revista de Nutrição, Campinas, v. 25, n. 3, p. 341-351, 2012.

PINTO, M. S.; BOSI, M. L. M. Muito mais do que pe(n)sam: percepções e experiências acerca da obesidade entre usuárias da rede pública de saúde de um município do Nordeste do Brasil. Physis, Rio de Janeiro, v. 20, n. 2, p. 443-457, 2010.

SOUZA, R. K. T. et al. Prevalência de fatores de risco cardiovascular em pessoas com 40 anos ou mais de idade, em Cambé, Paraná (2011): estudo de base populacional. Epidemiologia e Serviços de Saúde, Brasília, DF, v. 3, n. 22, p. 435-444, 2013.

VIEIRA, C. M.; TURATO, E. R. Percepções de pacientes sobre alimentação no seu processo de adoecimento crônico por síndrome metabólica: um estudo qualitativo. Revista de Nutrição, Campinas, v. 23, n. 3, p. 425-432, 2010.

\section{Contribuição dos autores}

Araujo e Garanhani delinearam o estudo, desenvolveram os roteiros de entrevistas, analisaram as transcrições e redigiram o manuscrito. González e Silva apoiaram a análise das transcrições e a redação do manuscrito. Todos os autores aprovaram a versão final do artigo.

Recebido: 16/02/2019

Aprovado: 28/02/2019 